\title{
PENGARUH KOMPETENSI PEDAGOGIK GURU TERHADAP HASIL BELAJAR IPA SISWA KELAS III SDN060915 JL. T.B SIMATUPANGKECAMATANMEDAN SUNGGAL TAHUN PEMBELAJARAN2018/2019
}

\author{
OLEH: \\ KRISTINA PERONIKA NAIBAHO ${ }^{1}$, PATRI JANSON SILABAN ${ }^{2 *}$ \\ (UNIVERSITAS KATOLIK SANTO THOMAS MEDAN ${ }^{1,2}$ )
}

\begin{abstract}
This study aims to find out how the pedagogical competencies of teachers at SDN 060915 JL TB. SimatupangKecamatan Medan Sunggal and how the influence of teacher pedagogic competence on student learning outcomes in class III science subjects SDN 060915 JL. TB Simatupang Medan Sunggal District. The approach used is quantitative with the survey method. The population in this study were all students at SDN 060915 JL. TB Simatupang, Medan SunggalSubdistrict, totaling 198 students. The sample was 45 students with a sampling technique that was simple random sampling. Data collection techniques in this study used a questionnaire (questionnaire) and documentation study. The analytical technique used is the data prerequisite test, product moment correlation test and hypothesis testing using the version 21.0 of the Program For Social Science (SPSS) statistics. From the results of the research that has been found it can be concluded that the pedagogical competence of teachers in science subjects is $51.11 \%$ with sufficient categories while the learning outcomes of class III students and class IIIB are $60 \%$ with sufficient categories. Based on the analysis of the data seen from the R Squaree determination coefficient test there is an influence of the teacher's pedagogical competence on learning outcomes, the magnitude of the influence is $23.8 \%$.
\end{abstract}

Keywords: Pedagogic Competence, Learning Outcomes

\section{PENDAHULUAN}

\section{Latar Belakang Masalah}

Pendidikan merupakan hak setiap warga negara untuk mendapatkan pendidikan yang layak. Kemajuan dunia pendidikan menciptakan manusiamanusia bermartabat mulia yang memiliki potensi tinggi untuk kemajuan bangsa, sehingga dapat meningkatkan mutu pendidikan. Pendidikan tidak pernah lekang dari setiap manusia karena pendidikan adalah sesuatu hal yang sangat penting. Proses pendewasaan seorang anak diperoleh dari pendidikan. Pendidikan dapat 
mengubah seorang anak menjadi berilmu, dewasa, kreatif, mandiri dan bertanggung jawab sesuai dengan tujuan dari pendidikan, sehingga memperoleh kehidupan yang jauh lebih baik. Menurut Dewantara (Pidarta 2013:11) Pendidikan adalah menuntun segala kodrat yang ada pada anak-anak, agar mereka sebagai manusia dan sebagai anggota masyarakat mendapat keselamatan dan kebahagian yang setinggi-tingginya.

Dalam Undang-Undang RI No. 20 tahun 2003 tentang sistem Pendidikan Nasional dikatakan bahwa: Pendidikan adalah usaha sadar dan terencana untuk mewujudkan suasana belajar dan proses pembelajaran terencan agar peserta didik secara aktif mengembangkan potensi dirinya untuk memiliki kekuatan spritual keagamaan, pengendalian diri, kepribadian, kecerdasan, ahlak mulia, serta keterampilan yang diperlukan dirinya, masyarakat, bangsa dan negara.

Untuk mengembangkan kemampuan yang dimiliki setiap warga, berbagai cara telah dilakukan dalam dunia pendidikan dimulai dari Sekolah Dasar hingga Perguruan Tinggi. Di Sekolah Dasar ada beberapa mata pelajaran yang wajib diajarkan.Salah satunya adalah Ilmu Pengetahuan Alam (IPA). IPA berkaitan erat dengan kehidupan manusia dalam kehidupan sehari-hari di masyarakat. Menurut Nurhahayati dan Hisbullah (2018: 2), IPA adalah hasil tanggapan pikiran manusia atas gejala yang terjadi di alam, seorang ahli IPA (Ilmuan) dapat memberikan sumbangan besarkepada IPA tanpa harus melakukan sendiri suatu percobaan, tanpa membuat sesuatu alat atau tanpa melakukan observasi. Sedangkan menurut Nokes (Hisbullahdan Nurhahayati2018: 2) menyatakan bahwa "pembelajaran IPA seyogianya melibatkan siswa dalam berbagai ranah, yaitu ranah kognitif, psikomotorik, dan afektif'. Hal ini dikuatkan dalam kurikulum IPA yang menganjurkan bahwa pembelajaran IPA di sekolah 
melibatkan siswa dalam penyelidikan yang beriorientasi inkuiri, dengan interaksi antara siswa dengan guru dan siswa lainnya.

Berdasarkan observasi peneliti selama tiga kali kunjungan pada SDN 060915 JL.T.B Simatupang Kecamatan Medan Sunggal, padakenyataanya dilapangan seorang guru yang mempunyai kompetensi pedagogik yang baik dalam melakukan proses pembelajaran adalah hal yang tidak mudah untuk ditemukan. Penguasaan kompetensi pedagogik guru ini juga dipengaruhi oleh beberapa faktor baik mengenai latar belakang pendidikan, masa kerja atau pengalaman kerja yang telah dijalani oleh seorang guru tersebut. Ketidak efektifan kompetensi pedagogik guru dalam mengajar terlihat pada proses pembelajaran yang tidak terencana dimana guru tidak memiliki tahapan-tahapan dalam mengajar seperti yang dimuat dalam rencana pelaksanaan pembelajaran (RPP). Ketidak efektifan guru juga terlihat pada pemahaman guru terhadap siswa dimana guru jarang sekali memberikan pujian kepada siswa. Kita tahu dengan memberikan pujian kepada siswa akan membangkitkan semangat dan rasa percaya diri siswa, dalam proses belajar mengajar juga kerap kali tidak ada hubungan timbal balik, hal tersebut diakibatkan karena guru tidak melibatkan siswa dalam proses pembelajaran, guru hanya melakukan metode ceramah yang dimana guru yang terus-menerus berbicara sedangkan siswa hanya duduk diam mendengarkan guru, keadaan tersebut tentu membuat siswa mudah bosan dan mengantuk. Seorang guru tentunya harus mampu membina hubungan yang baik antar siswa agar proses pembelajaran dapat berjalan dengan baik.

Masalah dalam mengajar juga terlihat pada guru dalam pengembangan perangkat pembelajaran yang kurang efektif seperti halnya dengan penyusunan 
RPP dan Silabus. Perangkat pembelajaran terkadang tidak sesuai dengan kemampuan siswa. Pengembangan pembelajaran ini juga menuntut tanggap terhadap perkembangan ilmu pengetahuan dan juga teknologi akan tetapi dalam situasi ini terdapat guru yang belum mampu dalam mengoperasikan teknologi seperti mengoperasikan komputer/laptop, dan proyektor, keadaan guru yang tidak mampu mengoperasikan teknologi, otomatis tidak dapat membuat pembelajaran yang menarik untuk ditampilkan kepada siswa seperti halnya dengan penampilan PowerPoint yang dapat memuat gambar, tulisan dengan berbagai warna yang begitu menarik perhatian siswa, serta berbagai bentuk Video Pembelajaran yang menarik yang dapat membuat siswa lebih fokus.

Keadaan di atas sangat merugikan bagi siswa, siswa seharusnya dididik seutuhnya, mendapatkan ilmu pengetahuan dengan mudah dari guru akan tetapi kenyataan berbanding terbalik dengan keadaan. Sepantasnya seorang pendidik harus mampu dalam bidangnya dan seorang guru itu harus memiliki kompetensi yang relevan sebagai pendidik, karena guru merupakan komponen paling menentukan dalam sistem pendidikan secara keseluruhan. Untuk dapat melaksanakan tugas dan tanggung jawab di atas, maka dari itu seorang guru dituntut memiliki beberapa kemampuan dan kompetensi tertentu.

Undang-undang No. 14 Tahun 2005 tentang Guru dan Dosen mengemukakan kompetensi pedagogik adalah "kemampuan mengelola pembelajaran peserta didik". Kompetensi Pedagogik merupakan salah satu jenis kompetensi yang mutlak perlu dikuasai guru karena kompetensi pedagogik adalah kemampuan mengelola pembelajaran peserta didik yang meliputi pemahaman terhadap peserta didik, perencanaan dan pelaksanaan pembelajaran, evaluasi hasil 
belajar, dan pengembangan peserta didik untuk mengaktualisasikan berbagai potensi yang dimilikinya. Keharusan guru memiliki kemampuan pedagogik banyak disinggung oleh ahli seperti yang dikemukakan oleh Imas dan Sani (2015:8-9) menyatakan bahwa kompetensi pedagogik merupakan kemampuan pemahaman yang berkaitan dengan pemahaman peserta didik dan pengelolaan pembelajaran yang mendidik dan dialogis. Dan ketika kita menemukan guru seorang pengajar atau guru yang tidak memahami karakter peserta didik, tidak bisa mejelaskan materi pelajaran dengan baik, tidak mampu memberi evaluasi terhadap apa yang sudah diajarkan, dan tidak dapat mengembangkan kompetensi yang dimiliki oleh peserta didik maka guru yang bersangkutan belum memiliki kompetensi pedagogik secara memadai.

Guru juga berkewajiban untuk mengembangkan kompetensi yang dimilikinya. Pengembangan mutlak diperlukan agar guru dapat melakukan tugasnya dengan baik dan dapat melakukan perubahan atau perbaikan dalam setiap kegiatan pembelajarannya. Kompetensi pedagogik guru menjadi faktor yang sangat menunjang peningkatan kualitas sekolah. Kompetensi pedagogik guru akan membawa guru dapat memilih cara terbaik yang dapat dilakukan supaya kegiatan pembelajaran dapat berjalan baik dan meningkatkan potensi siswa.

Adapun kompetensi pedagogik yang harus dimiliki setiap guru guna memperoleh hasil belajar siswa yang memuaskan maka diperlukan guru yang berkualitas atau berkompetensi dalam mengelola pembelajaran dengan baik, oleh karena itu penting kiranya seorang guru untuk menguasai kompetensi pedagogik guru yang mutlak harus dimiliki oleh guru profesional. Karena semakin tinggi 
kemampuan belajar siswa dan kualitas pengajaran di sekolah, maka semakin tinggi pula hasil belajar siswa. Beberapa komponen kompetensi pedagogik yang harus di kuasai seorang guru adalah sebagai berikut: 1) Pemahaman wawasan atau landasan pendidikan. 2) Pemahaman terhadap peserta didik, pengembangan kurikulum. 3) Perancangan pembelajaran. 4) pelaksanaan pembelajaran yang mendidik dan dialogis. 5) Pemanfaatan teknologi pembelajaran. Dan 6) Evaluasi hasil belajar.

Melihat sangat besarnya pengaruh kompetensi pedagogik guru terhadap hasil belajar siswa maka peneliti melakukan penelitian tentang kompetensi pedagogik guru di kelas 3. Guru sebagai tenaga pengajar sangat berperan aktif dalam peningkatan hasil belajar siswa. Dalam peningkatan hasil belajar siswa diharapkan guru dapat menunjukkan kompetensi pedagogik yang dimilkinya dalam proses belajar mengajar di dalam kelas agar siswa dapat menerima pelajaran dengan baik. Akan tetapi, peran siswa di dalam kelas juga berpengaruh terhadap peningkatan hasil belajar, dengan kata lain siswa juga harus mau mengikuti pembelajaran dengan baik.

Kompetensi pedagogik guru yang kurang efektif akan mempengaruhi hasil belajar peserta didik, apabila guru tidak memiliki kompetensi pedagogik yang baik maka proses belajar dan mengajar di kelas juga akan mengalami kendala yang membuat siswa bosan untuk belajar.Bertitik tolak latar belakang di atas, maka peneliti berkeinginan untuk meneliti dengan judul "Pengaruh Kompetensi Pedagogik Guru Terhadap Hasil Belajar Siswa Pada Mata Pelajaran IPA Siswa Kelas III SDN 060915 JL. T.B Simatupang Kecamatan Medan Sunggal Tahun Pembelajaran 2018/2019”. 


\section{Identifikasi Masalah}

Berdasarkan paparan latar belakang masalah yang telah dikemukakan, maka diperoleh beberapa permasalahan yang dapat diidentifikasi sebagai berikut:
a) Kurang efektifnya pembelajaran
b) Pengembangan perangkat pembelajaran yang kurang efektif
c) Penggunaan teknologi yang kurang efektif
d) Rendahnya hasil belajar mata pelajaran IPA

\section{Batasan Masalah}

Banyak faktor yang mempengaruhi hasil belajar siswa baik dari diri siswa itu sendiri maupun pengaruh dari lingkungannya. Namun karena luasnya bidang cakupan serta adanya berbagai keterbatasan yang ada baik waktu, dana, maupun jangkauan peneliti. Dalam penelitian ini dibatasi masalah pengaruh kompetensi pedagogik guru. Terhadap Hasil Belajar Siswa Pada Mata Pelajaran IPA Siswa di kelas III SDN 060915 JL.T.B Simatupang Kecamatan Medan Sunggal Tahun Pembelajaran 2018/2019.

\section{Perumusan Masalah}

Berdasarkan latar belakang masalah tersebut di atas, maka dapat diidentifikasi masalah sebagai berikut: Adakah pengaruh kompetensi pedagogik guru terhadap hasil belajar siswa kelas III di SDN 060915 JL.T.B Simatupang Kecamatan Medan Sunggal Tahun Pembelajara 2018/2019?

\section{Tujuan Penelitian}

Merujuk pada rumusan masalah di atas, maka dapat ditentukan tujuan penelitian sebagai berikut: Untuk mengetahui adakah pengaruh kompetensi 
pedagogik guru terhadap hasil belajar siswa kelas III 060915 JL.T.B Simatupang Kecamatan Medan Sunggal Tahun Pembelajaran 2018/2019.

\section{METEDOLOGI PENELITIAN}

\section{Pendekatan dan Metode Penelitian}

Pendekatan penelitian ini adalah penelitian kuantitatif. Menurut Sugiyono (2017:9). "Metode kuantitatif dapat diartikan sebagai metode penelitian yang berlandaskan pada filsafat positivisme, digunakan untuk meneliti pada populasi atau sampel tertentu, pengumpulan data menggunakan instrumen penelitian, analisis data berifat kuantitatif/statistik, dengan tujuan untuk menguji hipotesis yang telah ditetapkan”.

Metode penelitian merupakan suatu cara atau langkah yang ditempuh dalam mengumpulkan, mengorganisasikan, serta menginterpretasikan data. Menurut Sugiyono(2017:2) "Metode penelitian pada dasarnya merupakan cara ilmiah untuk mendapatkan data dengan tujuan dan kegunaan tertentu'.Maka metode penelitian yang digunakan dalam penelitian ini adalah penelitian deskriptif. Penelitian ini merupakan jenis penelitian kuantitatif, dengan jenis analisis korelasi dikarenakan ada hubungan sebab akibat antara dua variabel (bivariate correlation)penelitian ini ada dua macam variabel, yaitu variabel bebas (independent) dan variabel terikat (dependent).

\section{Lokasi dan Jadwal Penelitian}

Penelitian dilakukan di SDN 060915 JL. T.B Simatupang Kecamatan Medan Sunggal. Adapun alasan peneliti memilih tempat tersebut sebagai lokasi penelitian adalah sebagai berikut: 
a. Jumlah siswa di SDN 060915 JL. T.B Simatupang Kecamatan Medan Sunggal cukup memadai untuk dijadikan sampel penelitian.

b. Belum pernah dilakukan penelitian ini di SDN 060915 JL. T.B Simatupang Kecamatan Medan Sunggal.

Waktu pelaksanaan penelitian ini diperkirakan berlangsung \pm 3 Bulan yaitu pada bulan Maret sampai dengan Mei semester ganjil tahun ajaran 2018/2019 yang disesuaikan dengan jadwal pelajaran di sekolah.

\section{Rancangan dan Desain Penelitian}

Dalam penelitian ini terdapat variabel bebas dan variabel terikat. Variabel bebas (independen) merupakan variabel yang mempengaruhi variabel terikat.Variabel terikat (dependen) merupakan variabel yang dipengaruhi variabel bebas. Variabel ini biasanya disimbolkan dengan variabel "y".Adapun variabelvariabel yang digunakan dalam penelitian ini terdiri dari variabel bebas (independen) yakni Kompetensi pedagogik guru (X), sedangkan variabel terikat (dependen) yakni hasil belajar siswa (Y).

\section{Populasi dan Teknik Pengambilan Sampel}

Populasi dalam penelitian ini adalah semua siswa kelas III SDN 060915 JL. T.B Simatupang Kecamatan Medan Sunggal Tahun Pelajaran 2018 yang berjumlah 45 siswa. Teknik pengambilan sampel yang digunakan peneliti dalam penelitian ini adalah simple Random Sampling. Berdasarkan hasil observasi disekolah jumlah siswa yang ada disekolah tersebut sebanyak 198 siswa. Sehingga peneliti mengambil sampel sebagai responden sebanyak 45 siswa yaitu siswa pada kelas III yakni kelas III-A (24 orang) dan kelas III-B (21 orang). 


\section{Jenis dan Sumber data}

Penelitian akan menggunakan sumber data yaitu data primer yang didapat langsung dari subjek peneliti. Sumber data dalam penelitian ini berasal dari sekolah tempat peneliti. Jumlah populasi sebanyak 45 orang siswa yang ada di kelas III SDN 060915 JL. T.B Simatupang Kecamatan Medan Sunggal, maka sumber data dalam penelitian ini adalah 45 orang siswa yang terdapat di III-A dan kelas III-B.

\section{Teknik dan Alat Pengumpul Data}

Pengumpulan data yang dilakukan untuk mendapatkan berbagai informasi dalam penelitian ini yaitu observasi, wawancara, dokumentasi, dan gabungan/triangulasi.

Pengumpulan data dalam penelitian perlu dilakukan untuk memperoleh data atau informasi. Untuk memperoleh data diperlukan sebuah alat atau instrumen. Mulyatiningsih (2014:24) mengatakan bahwa "alat pengumpul data berarti instrumen atau perangkat yang digunakan untuk mengumpulkan data". Adapun alat atau instrumen pengumpulan data yang dilakukan peneliti dalam penelitian ini yaitu: Angket dimana pemberian skor atau skala penilaian pada setiap pertanyaan ataupun pernyataan dalam angket tersebut adalah:

Tabel Jabaran Tingkatan Skala

\begin{tabular}{|l|c|c|c|}
\hline NO & Skala & Keterangan & Angka \\
\hline 1 & SS & Sangat Setuju & 4 \\
\hline 2 & S & Setuju & 3 \\
\hline 3 & TS & Tidak Setuju & 2 \\
\hline 4 & STS & Sangat Tidak Setuju & 1 \\
\hline
\end{tabular}




\section{Uji Instrumen Penelitian}

\section{Uji Validitas}

Untuk mengetahui validitas instrumen digunakan teknik korelasi product moment dengan angka kasar yang dikemukakan oleh Pearson sebagai berikut:

$\mathrm{r}_{\mathrm{xy}}=\frac{\mathrm{N} \Sigma \mathrm{XY}-(\Sigma \mathrm{X})(\Sigma \mathrm{Y})}{\left\{\mathrm{N} \Sigma \mathrm{X}^{2}-\left(\Sigma \mathrm{X}^{2}\right)\right\}\left\{\left(\mathrm{N} \Sigma \mathrm{Y}^{2}-\left(\Sigma \mathrm{Y}^{2}\right)\right\}\right.} \ldots \ldots \ldots \ldots . . .($ Arikunto, $2014: 213)$

Keterangan:

$\mathrm{r}_{\mathrm{xy}}=$ koefisien korelasi antara variabel $\mathrm{x}$ dan $\mathrm{y}$

$\Sigma x y=$ jumlah perkalian $\mathrm{x}$ dengan $\mathrm{y}$

$\mathrm{X}=$ skor tiap item

$\mathrm{Y}=$ skor total

$\mathrm{N}$ = sampel

\section{Uji Reliabilitas}

Reliabilitas soal merupakan ukuran yang menyatakan kekonsistenan suatu soal tes untuk menguji reliabilitas instrumen digunakan rumus Alpha. Menurut Arikunto (2014:239) "rumus alpha digunakan untuk mencari reliabilitas instrumen yang skornya bukan 1 dan 0 , misalnya angket atau soal bentuk uraian”.Rumus Alpha sebagai berikut:

$\mathrm{r}_{11}=\left(\frac{K}{(K-1)}\right)\left(1-\frac{\sum \sigma_{b^{2}}}{\sigma^{2} t}\right)$ (Arikunto, 2014:239)

Keterangan:

r11 = reliabilitas instrumen

$\sum \sigma_{b^{2}} \quad=$ jumlah varians total

$\sigma t^{2} \quad=$ Varians total 
$\mathrm{k} \quad$ = banyaknya butir pertanyaan a

Untuk mencari varians item digunakan rumus:

$\sigma \frac{2}{b}=\frac{\sum \mathrm{X}-\frac{\left(\sum \mathrm{X}\right)^{2}}{\mathrm{~N}}}{\mathrm{~N}},($ Arikunto $2016: 23)$

Keterangan:

$\mathrm{N}=$ Banyaknya siswa

$\sigma_{b}^{2}=$ Varians tiap item

$\mathrm{X}=$ Nilai tiap butir soal

Dan untuk mencari varians total $\left(\sigma_{t}^{\frac{2}{-}}\right)$ dipergunakan rumus sebagai berikut:

$\sigma_{t}^{2}=\frac{\sum Y^{2}-\left(\sum Y\right)^{2}}{N},($ Arikunto 2016:23)

Keterangan:

$\mathrm{N}=$ Banyak siswa

$\sigma_{t}^{\frac{2}{t}}=$ Varians total

$\mathrm{Y}^{2}=$ Nilai total butir soal

Interpretasi koefisien reliabilitas terhadap hasil perhitungan nilai koefisien korelasi $\mathrm{r}_{11}$ mengacu pada pendapat Arikunto (2016: 89) sebagai berikut:

Tabel Interpretasi Koefisien Reliabilitas

\begin{tabular}{|l|l|l|}
\hline No & Angka Korelasi & \multicolumn{1}{c|}{ Rentang Kategori } \\
\hline 1 & $0,800-1,000$ & Sangat tinggi \\
\hline 2 & $0,600-0,800$ & Tinggi \\
\hline 3 & $0,400-0,600$ & Cukup rendah \\
\hline 4 & $0,200-0,400$ & Rendah \\
\hline 5 & $0,000-0,200$ & Sangat rendah (tak berkolerasi) \\
\hline
\end{tabular}

Sumber: Arikunto (2016: 89) 


\section{Uji Prasyarat Data}

\section{Uji Normalitas}

Nilai Asymp. Signini menguji signifikansi pada hasil perhitungan Kolmogav-Smirnov test.

$\mathrm{X}^{2}=\sum_{i=1}^{k} \frac{\left(f_{o-f_{e}}\right) 2}{f_{e}}$

Keterangan:

$\mathrm{X}^{2} \quad=$ Kuadrat-Chi

$\mathrm{f}_{0} \quad=$ frekuensi yang diobservasi

$\mathrm{f}_{\mathrm{e}} \quad=$ frekuensi yang diharapkan

\section{Uji Linearitas}

Uji linearitas dilakukan untuk mengetahui apakah variabel bebas $(\mathrm{X})$ dan variabel (Y) mempunyai hubungan yang linear atau tidak. Untuk mencari $F_{\text {hitung }}$ dilakukan dengan bantuan program SPSS ver. 21.0.Rumus uji linearitas data adalah sebagai berikut:

$\mathrm{F}_{\text {reg }}=\frac{R K_{\text {reg }}}{R K_{\text {res }}}$

Keterangan:

$\mathrm{F}_{\text {reg }} \quad=$ harga $\mathrm{F}$ untuk garis regresi

$\mathrm{Rk}_{\mathrm{reg}} \quad=$ rerata kuadratgaris regresi

$\mathrm{Rk}_{\mathrm{res}} \quad=$ rerata kuadrat garis residu

Harga $\mathrm{F}_{\text {hitung }}$ kemudian dikonsultasikan dengan $\mathrm{F}_{\text {tabel }}$ pada taraf signifikan $5 \%$.Jika $F_{\text {hitung }}$ lebih kecil atau sama dengan $F_{\text {tabel }}\left(F_{\text {hitung }} \leq F_{\text {tabel }}\right)$, berarti kedua variabel dapat disimpulkan mempunyai hubungan yang linier. Sebaliknya jika 
$F_{\text {hitung }}$ lebih besar dari $\mathrm{F}_{\text {tabel }}\left(\mathrm{F}_{\text {hitung }}>\mathrm{F}_{\text {tabel }}\right)$ berarti dapat disimpulkan kedua variabel tidak mempunyai hubungan yang linier.

\section{Teknik Pengolahan (analisis) Data}

Penelitian ini dilakukan dengan bantuan program SPSSver. 21.0 for windowsdan Ms. Exel 2007. Sebelum dilakukan uji-t, terlebih dahulu dilakukan uji prasyarat analisis yaitu uji normalitas dan uji homogenitas data.

\section{Uji Korelasi}

Untuk mengetahui ada tidaknya pengaruh antara variabel bebas (X) dengan variabel terikat (Y), dengan rumus korelasi Product Moment yaitu:

$$
r_{x y}=\frac{N \sum X Y-\left(\sum X\right)\left(\sum Y\right)}{\sqrt{\left\{N \sum X^{2}-\left(\sum X\right)^{2}\right\}\left(N \sum Y^{2}-\left(\sum Y\right)^{2}\right\}}} \ldots \ldots \ldots . . .(\text { Arikunto, 2016: 87) }
$$

Keterangan:

$\mathrm{r}_{\mathrm{xy}}=$ Koefisien korelasi product moment

$\mathrm{N} \quad=$ Jumlah seluruh siswa

$\sum \mathrm{X}=$ Skor item

$\sum \mathrm{Y}=$ Skor total seluruh siswa

$\sum X Y=$ Jumlah hasil perkalian antara skor "X" dan skor "Y"

\section{Uji Hipotesis}

Metode analisis data dalam penelitian ini menggunakan uji hipotesis. Pengujian hipotesis bertujuan untuk mengetahui apakah kompetensi pedagogik guru berpengaruh secara signifikan terhadap hasil belajar IPA.Dengan rumus uji signifikasi korelasi product moment. Dengan bantuan program SPSSver. 21.0. Adapun rumusnya, Sugiyono (2018: 184) sebagai berikut : 


$$
t=\frac{r \sqrt{n-2}}{\sqrt{1-r^{2}}}
$$

Jika $\mathrm{t}$ hitung $>\mathrm{t}$ tabel ; hipotesis alternatif diterima

Jika t hitung $<\mathrm{t}$ tabel $;$ hipotesis alternatif ditolak

\section{HASIL PENELITIAN}

Penelitian ini dilakukan di SDN 060915 JL. TB. Simatupang kecamatan medan sunggal. Peneliti menggunakan kuesioner sebagai alat pengumpulan data dengan jumlah sampel penelitian sebanyak 45 peserta didik. Pengambilan sampel menggunakan Sampling jenuh. Tujuan penelitian melakukan penelitian ini untuk mengetahui tingkat kompetensi pedagogik guru dan hasil belajar siswa serta pengaruh kompetensi pedagogik guru terhadap hasil belajarr peserta didik di SDN 060915 JL. TB. Simatupang kecamatan medan sunggal.

a. Kompetensi Pedagogik Guru

Kompetensi pedagogik merupakan kemampuan seorang guru dalam melaksanakan kewajiban-kewajibannya secara bertanggung jawab dan layak. Semakin baik kompetensi pedagogik guru maka semakin baik pula kemampuan yang akan dimilikinya. Hal ini dikarenakan guru tersebut akan melaksanakan kegiatan pendidikan dn pengajaran dengan baik, mampu menguasai karakterristik peserta didik, menguasai teori belajar dan prinsip-prinsip pembelajaran yang mendidik, pengembangan kurikulum, pengembangan potensi peserta didik, komunikasi dengan peserta didik mampu menggunakan hasil evaluasi untuk meningkatkan kualitas mengajarnya, yang pada akhirnya dapat meningkatkan kinerjannya. 
Dalam penelitian ini diperoleh beberapa hasil sesuai dengan rumusan masalah serta tujuan penelitian yang telah dijelaskan pada bab satu. Dari hasil analisis menunjukkan bahwa kompetensi pedagogik guru pada frekuensi $(8,88 \%)$ menilai bahwa kompetensi pedagogik guru sangat rendah, frekuensi $(26,66 \%)$ menilai bahwa kompetensi pedagogik guru rendah, frekuensi $(51,11 \%)$ menilai bahwa kompetensi pedagogik guru cukup, dan frekuensi (13,33 \%)kompetensi pedagogik guru tinggi, tingkat kemampuan yang cukup pemahaman peserta didik tinggi. Maka berdasarkan paparan tersebut dapat disimpulkan bahwa kompetensi pedagogik guru bidang studi IPA SDN 060915 JL TB Simatupang Kecamatan Medan Sunggal adalah cukup.

b. Hasil Belajar

Dari hasil analisis menunjukkan bahwa hasil belajar siswa pada frekuensi $(6,66 \%)$ sangat rendah, frekuensi $(15,55 \%)$ menunjukkan hasil belajar yang rendah, frekuensi (60\%) menunjukkan hasil belajar yang cukup, dan frekuensi $(17,77 \%)$ menunjukkan hasil belajar yang tinggi,Maka berdasarkan paparan tersebut dapat disimpulkan bahwa hasil belajar siswa pada bidang studi IPA SDN 060915 JL TB Simatupang Kecamatan Medan Sunggal adalah cukup.

Dari hasil pengujian yang dilakukan dapat diketahui antara kompetensi pedagogik guru dengan hasil belajar siswa memiliki pengaruh yang saling berkaitan erat. dimana semakin buruk kompetensi yang dimiliki guru semakin rendah hasil belajar siswa yang diperoleh dan sebaliknya semakin baik kompetensi guru semakin baik juga hasil belajar siswa. 


\section{PENUTUP}

\section{Kesimpulan}

Berdasarkan hasil dan pembahasan penelitian tentang Pengaruh kompetensi pedagogik guru terhadap hasil belajar IPA siswa kelas III SDN 060915 JL. TB Simatupang Kecamatan Medan Sunggal, dengan analisis data dapat disimpulkan sebagai berikut:

1. Kompetensi pedagogik guru kelas III SDN 060915 JL. TB Simatupang Kecamatan Medan Sunggal dalam kategori cukup. Hal ini dapat dilihat dari beberapa aspek seperti dalam hal pemahaman terhadap peserta didik, perancangan pembelajaran, pemanfaatan teknologi pembelajaran, evaluasi hasil belajar, serta pengembangan peserta didik dan lain sebagainnya, jawaban responden paling banyak yaitu kategori cukup mencapai 51,11\%

2. Hasil belajar IPA siswa kelas III SDN 060915 JL. TB Simatupang Kecamatan Medan Sunggal dalam kategori cukup. Hal ini dapat dilihat dari hasil belajar IPA yang peneliti peroleh dari nilai raport pada semester ganjil, lebih dari sebagian siswa yang nilainya rata-rata KKM dan hanya ada beberapa siswa saja yang mencapai KKM yang ditentukan, serta $60 \%$ menunjukkan bahwa hasil belajar IPA siswa dalam kategori cukup.

3. Kompetensi pedagogik guru kelas berpengaruh terhadap hasil belajar IPA siswa kelas III SDN 060915 JL. TB Simatupang Kecamatan Medan Sunggal. Hal ini dibuktikan dengan hasil uji korelasi product moment diperoleh nilai koefisien korelasi (rxy) sebesar0,488, nilai rxy tersebut lebih besar apabila dibandingkan dengan $r$ tabel pada taraf signifikansi 5\% yaitu 0,294. dengan demikian Ha yang diajukan diterima, sedangkan Ho di tolak. 
Maka dapat disimpulkan bahwa ada korelasi positif antara kompetensi pedagogik guru kelas dengan hasil belajar IPA siswa kelas III SDN 060915 JL. TB Simatupang kecamatan medan sunggal.Selain itu uji hipotesis juga membuktikan bahwa hasil uji hipotesisi memiliki nilai $t_{\text {hitung }}$ sebesar 3,642. Jika nilai itu dikonsultasikan dengan nilai $t_{\text {tabel }}$ pada derajat kebebasan $($ degree of freedom $)=43$ sebesar 1,681 maka $t_{\text {hitung }}(3,642)>\mathrm{t}_{\text {tabel }}(1,681), \mathrm{H}_{0}$ ditolak. Itu berarti ada pengaruh yang signifikan antara kompetensi pedagogik guru terhadap hasil belajar.

\section{Saran}

Berdasarkan simpulan, implikasi, dan keterbatasan penelitian yang sudah dipaparkan, maka dapat diberikan saran-saran sebagai berikut:

1. Bagi sekolah, diharapkan pihak sekolah untuk memberikan pelatihanpelatihan kepada guru untuk meningkatkan kompetensi dalam mendidik agar hasil belajar siswa meningkat

2. Bagi Siswa, dengan mengetahui adanya pengaruh kompetensi pedagogik guru terhadap hasil belajar siswa, siswa diharapkan mempunyai minat belajar tersendiri untuk mengembangakan prestasinya dibidang akademik maupun non akademik diluar sekolah

3. Bagi Pembaca, penelitian ini mengungkap pengaruh kompetensi pedagogik guru terhadap hasil belajar dengan kontribusi sebesar 23,8\%

4. Bagi Peneliti Selanjutnya, bagi peneliti yang selanjutnya dapat mengkaji dan mengembangkan hasil penelitian ini, serta perlu dilakukan penelitian pada mata pelajaran lain dan di sekolah yang berbeda. 


\section{DAFTAR PUSTAKA}

AdhePurnama Sari 2013.PengaruhPenguasaanKompetensiPedagogikGuru TerhadapHasilBelajar IPA PadaSiswaKelas $3 \quad$ Di SDMuhammadiyah16Karangsem Surakarta Tahun 2012/2013. Skripsi

Arikunto, Suharsimi. 2014. ProsedurPenelitianSuatuPendekatanPraktik. Jakarta: RinekaCipta.

Aunurrahman.2014. BelajardanPembelajaran.Bandung: Alfabeta.

Basri, Hasan. 2015. ParadigmaBaruSistemPembelajaran. Bandung: CV PustakaSetia

Khairani, Makmun. 2013. PsikologiBelajar. Jogjakarta: AswajaPressindo.

IstaranidanSamidi.2016.Kompetensi \&Profesionalisme Guru.Medan: Larispa.

Kurniasih, ImasdanSani, Berlin. 2015. RagamPengembangan Model Pembelajaran. Jogjakarta: Kata Pena

Majid, Abdul. 2017. PembelajaranTematikTerpadu. Bandung: PT.RemajaRosdakarya.

Mulyasa.2013.StandarKompetensidanSertifikasiGuru.Bandung:

PT.RemajaRosdakarya.

Mulyatinigsih, Endang. 2014. Metode Penelitian Terapan Bidang Pendidikan.Bandung:Alfabeta.

Pidarta,Made.2014.LandasanKependidikan. Jakarta:Rinekacipta.

Purwanto. 2017. EvaluasiHasilBelajar. Yogyakarta: PT.PustakaPelajar.

Rusman.2013. BelajardanPembelajaranBerbasisKomputer. Bandung: Alfabeta.

Rusman.2017.BelajardanPembelajaranBerorientasiStandarProses

Pendidikan.Jakarta: PT.Kharisma Putra Utama.

SadullahUyoh,dkk.2018.Pedagogik.Bandung: Alfabeta.

Sardiman. 2017. Interaksi \& Motivasi Belajar Mengajar. Jakarta : PT. RajaGrafindoPersada.

Saud,SyaefudinUdin.2017.PengembanganProfesi Guru.Bandung: Alfabeta. 
Selvi, Nurhayati dan Hisbullah. 2018. Pembelajaran Ilmu Pengetahuan Alam Di Sekolah Dasar: Makassar: Penebit Aksara Timur.

Sudarma,Momon.2013: Profesi Guru Dipuji,Dikritisi, danDicaci.Jakarta:RajaGrafindoPersada.

Sudjana.2016. PenilaianHasil Proses BelajarMengajar. Bandung: PT.RemajaRosdakarya

Sujana, Asep. 2014. Dasar-Dasar IPA Konsep dan Aplikasinya. Bandung: UPI PRESS

Sumanto. 2014. StatistikaTerapan. Yogyakarta: PT.BukuSeru.

Suprijono, Agus. 2014. Cooperative Learning Teori \& Aplikasi PAIKEM. Yogyakarta: Pustaka Pelajar.

Susanto, Ahmad. 2015. TeoriBelajardanPembelajaran di SekolahDasar. Jakarta: Prenadamedia Group.

Sugiyono. 2016. Cara MudahMenyusunSkripsi, Tesis, danDisertasi. Bandung: Alfabeta.

Sugiyono. 2017. MetodePenelitianKuantitatif, Kualitatif, dan R\&D. Bandung: Alfabeta.

Sugiyono. 2017. MetodePenelitianKuantitatif, kualitatif, dan R\&D. Bandung: Alfabeta

Suyanto danAsep Jihad.2013.Menjadi Guru profesional.Jakarta.Erlangga.

WindhiAlfianti 2017. Melakukanpenelitiandenganjudul "PengaruhKompetensiPedagogik Guru TerhadapHasilBelajarSiswaKelas IV SDN 2 NologatenPonorogoTahunPelajaran 2016/2017. Skripsi 